\title{
Research On Water-Immersion Softening Mechanism of Coal Rock Mass Based on Split Hopkinson Pressure Bar Experiment
}

\section{Zhiyuan Liu}

CUPB: China University of Petroleum Beijing

Gang Wang ( $\sim$ ckwanggang@163.com )

Shandong University of Science and Technology https://orcid.org/0000-0003-4742-8103

Jinzhou Li

CUPB: China University of Petroleum Beijing

Huaixing Li

Shandong University of Science and Technology

\section{Haifeng Zhao}

CUPB: China University of Petroleum Beijing

Hongwei Shi

CUPB: China University of Petroleum Beijing

Jianli Lan

CUPB: China University of Petroleum Beijing

\section{Research}

Keywords: Coal immersion softening, Dynamic compressive response, Split Hopkinson pressure bar, Softening Mechanism model

Posted Date: October 18th, 2021

DOI: https://doi.org/10.21203/rs.3.rs-966655/v1

License: (c) (1) This work is licensed under a Creative Commons Attribution 4.0 International License. Read Full License 


\section{Research on Water-immersion Softening Mechanism of Coal Rock Mass Based on Split Hopkinson Pressure Bar Experiment}

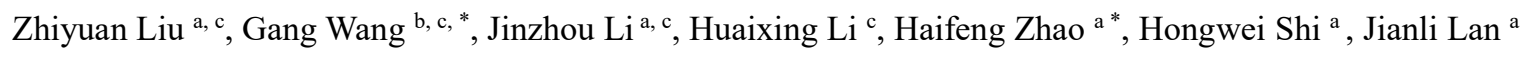
a School of Petroleum Engineering, China University of Petroleum Beijing, Beijing 102249, China b Shandong University of Science and Technology, Mine Disaster Prevention and Control-Ministry of State Key Laboratory Breeding Base, Qingdao 266590, China c Shandong University of Science and Technology, College of Safety and Environmental Engineering, Qingdao 266590, China

Abstract: The coal mining process is affected by multiple sources of water such as groundwater and coal seam water injection. Understanding the dynamic mechanical parameters of water-immersed coal is helpful to the safe production of coal mines. The impact compression tests were performed on coal with different moisture contents by using the $\phi 50 \mathrm{~mm}$ Split Hopkinson Pressure Bar (SHPB) experimental system, and the dynamic characteristics and energy loss laws of water-immersed coal with different compositions and water contents were analyzed. Through analysis and discussion, it is found that: (1) When the moisture content of the coal sample is $0 \%, 30 \%$, $60 \%$, the stress, strain rate and energy first increase and then decrease with time; (2) When the moisture content of the coal sample increases from $30 \%$ to $60 \%$, the stress "plateau" of the coal sample disappears, resulting in an increase in the interval of the compressive stress and a decrease in the interval of the expansion stress. (3) The increase of the moisture content of the coal sample will affect its impact deformation and failure mode. When the moisture content is $60 \%$, the incident rod end and the transmission rod end of the coal sample will have obvious compression failure, and the middle part of the coal sample will also experience expansion and deformation. (4) The coal composition ratio suitable for the impact experiment of coal immersion softening is optimized.

Keywords: Coal immersion softening; Dynamic compressive response; Split Hopkinson pressure bar; Softening Mechanism model

\section{Introduction}

Owing to the development of the coal mining industry, the depth of coal mining continues to increase, and the dynamic disasters of coal rock in coal mines are becoming more and more serious ${ }^{[1]}$. Understanding the dynamic mechanical parameters of coal rock is of great significance for preventing and reducing the occurrence of disasters. ${ }^{[2]}$. Coal is a porous, non-uniform and discontinuous medium composed of multiple mineral components. When the underground water level in the mining area rises, the coal is immersed in the water, and the free water penetrates 
into the pores and fissures of the coal. This promotes the expansion and connection of pores and fissures, changes the water content and permeability of the coal and rock mass, and reduces or even destroys the bearing capacity and strength of coal ${ }^{[3,4]}$.

In order to develop laboratory coal samples consistent with the properties of raw coal under complex geological conditions, a large number of researchers have studied the composition, production process, and mechanical

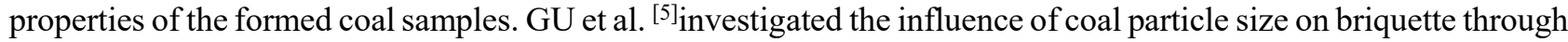
forming experiments on the change of particle size before and after the forming of pulverized coal and the forming of raw materials with different particle sizes. XU et al. ${ }^{[6]}$ pointed out that the smaller the particle size of the coal sample, the larger the fractal dimension of the pore structure of the briquette, and the higher the mechanical strength of the coal mass for abrupt failure. YU et al. ${ }^{[7]}$ carried out experiments on the permeability evolution of coal samples $^{[8]}$ with different particle size ratios. ZHAO et al. ${ }^{[9]}$ studied the effect of coal particle size on isothermal adsorption. XU et al. ${ }^{[10]}$ discussed the relationship between pulverized coal particles and pore structure, and pointed out that the smaller the particle size of the briquette, the smaller the pore radius in the briquette, but the higher the degree of pore structure development.

At the same time, some researchers have studied the influence of moisture on the mechanical properties of coal rock mass ${ }^{[11]}$. Erguler et al. ${ }^{[12]}$ quantified the influence of water content on the mechanical properties of rocks and pointed out that as the water increases, the compressive strength and elastic modulus of the samples will decrease. WANG et al. ${ }^{[13]}$ conducted uniaxial compression tests on raw coal and briquette with different moisture contents, and their results showed that moisture has a significant effect on the initial compaction, elasticity, and yield stages of coal sample deformation. Kim et al. ${ }^{[14]}$ studied the dynamic mechanical properties of sandstone at different water saturations. JIANG et al. ${ }^{[15]}$ pointed out that as the moisture content increases, the loading and unloading damage of coal samples increases, and the load-bearing strength and residual strength show a downward trend. LI et al. ${ }^{[16]}$ established a constitutive model of coal rock segmental damage under hydraulic-mechanical coupling. YIN et al. ${ }^{[17]}$ reported that there is an exponential relationship between the moisture content and the permeability of coal. QIN et al. ${ }^{[18]}$ examined the influence of moisture on the acoustic emission characteristics of coal and found that dry coal samples have more acoustic emission events than water-bearing coal samples ${ }^{[19]}$. PAN et al. ${ }^{[20]}$ suggested that the moisture in the coal matrix would cause the coal body to swell and deform. Perera et al. ${ }^{[21]}$ explored the mechanism of the effect of water saturation on the strength of coal, and found that the water in the coal extends to the tip of the crack through dissolution, thereby promoting crack propagation. ZHANG et al. ${ }^{[22]}$ pointed out that the softening and blocking effects of water make the free gas have an inhibitory effect on the deformation of soft coal. XIAO et al. ${ }^{[23]}$ established the corresponding relationship between the impact tendency of coal samples with different 
moisture contents and their acoustic emission signals.

The above-mentioned researchers have conducted in-depth research on the influencing factors of the physical properties of briquette. However, in the actual production activities of coal mining operations, the influence of dynamic factors such as mechanical shock, and rock fracture on coal destruction is more complicated ${ }^{[24]}$. Daryadel, ZHU, Mishra and Doner et al. ${ }^{[25-28]}$ analyzed the dynamic mechanical properties of the Split Hopkinson Pressure $\operatorname{Bar}(\mathrm{SHPB})^{[29]}$ on concrete specimens. AI et al. ${ }^{[30]}$ studied the crack propagation and dynamic mechanical properties of coal, and found that the direction of the bedding has a great influence on its dynamic compressive strength, strain rate and strain energy. YIN et al. ${ }^{[31]}$ tested the strain and energy dissipation characteristics of gas-bearing coal in the SHPB test by changing the gas pressure and static load. HAO et al. ${ }^{[32]}$ examined the effect of loading rate on the dynamic compressive strength and crack growth of coal samples. KONG et al. ${ }^{[33-35]}$ pointed out that under different confining pressures, gas pressures and impact loads, the failure strength and failure strain of coal samples increase linearly with the strain rate. ZHAO et al. ${ }^{[36]}$ explored the correlation between different bedding directions and dynamic tensile strength, and found that bedding roughness and discontinuity, impact speed, etc. would affect the dynamic mechanical properties of coal. FENG et al. ${ }^{[37,38]}$ reported that the axial fracture of the coal sample is directly caused by the incident compressive stress wave, and the lateral fracture is caused by the reflected tensile stress wave of the coal sample and the transmission rod. FAN and LI et al. ${ }^{[39,40]}$ comparatively analyzed the dynamic mechanical characteristics, destruction process and energy dissipation law of explosive coal and anti-explosive coal. WANG et al. ${ }^{[41]}$ suggested that under impact load, the dynamic strength of saturated sandstone should include the influence of its free water viscosity and Stefan effect. LIU et al. ${ }^{[42]}$ found that coal rock mostly exhibits axial splitting failure at low strain rates, and crush failure at high strain rates. LI et al. ${ }^{[43]}$ decomposed method to decompose the measured SHPB test signal of coal impact damage by using the empirical mode decomposition method.

In summary, researchers studied the mechanical structure characteristics of the laboratory coal sample matrix, namely coal. Some of them believe that moisture has a great influence on the mechanical properties of coal, mainly in the deformation stage, and investigate the characteristics of permeability evolution and soften in of coal in water. In order to further study the impact load characteristics of coal samples, researchers have carried out a large number of SHPB tests, mainly studying the influencing factors of the failure mode of coal. Therefore, in order to find a suitable laboratory sample replace the specimen wetted by the water injection of raw coal, the impact load of the coal sample is analyzed through the SHPB dynamic impact test in this paper. Starting from the composition and moisture content of the coal sample, the damage characteristics of the coal sample under impact load are analyzed and optimized, which is more in line with the type of the coal seam and rock mechanics standard coal proportioning 
plan. This lays the experimental material foundation for revealing the mechanism of coal seam water injection for disaster prevention and dust reduction.

\section{Design of dynamic mechanical test of water immersed coal}

\subsection{Split Hopkinson pressure bar test system}

The SHPB test device (shown in Figure 1) includes a pressure bar, super dynamic strain gauges, an oscilloscope and a data acquisition system. The diameter of the strut is $50 \mathrm{~mm}$, and the material of the bullet, strut, and absorption rod are the same. The elastic modulus is $206 \mathrm{MPa}$, the density is $7850 \mathrm{~kg} / \mathrm{m}^{3}$, the bullet length is $500 \mathrm{~mm}$, the incident and projection rod length is $3000 \mathrm{~mm}$, and the wave velocity is $7143 \mathrm{~m} / \mathrm{s}$. The principle of the SHPB test is as follows. At different impact speeds, the punch acts on the incident rod, and a stress wave is generated on the incident rod. After the stress wave contacts the specimen, the reflected wave and the incident wave are generated on the incident rod and the transmission rod, respectively, and the data acquisition system records the data of the strain gauges on each compression bar.

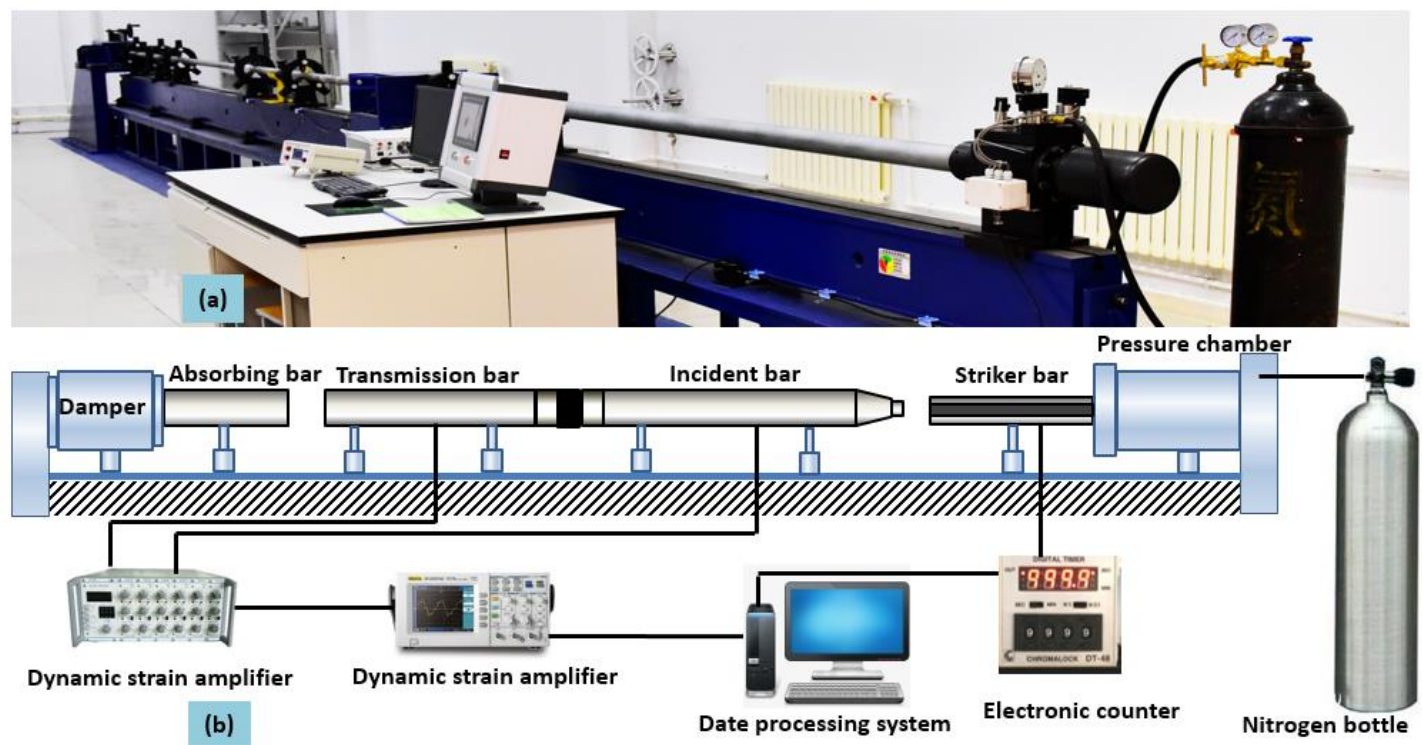

Figure 1 Split Hopkinson Pressure Bar test apparatus

(a) SHPB system equipment

(b) SHPB equipment schematic diagram

\subsection{Composition ratio of coal sample for immersion experiment}

The pulverized coal was taken from the N2808 working face of the 8\# anthracite coal seam of Yuyang Coal Mine of Chongqing Songzao Coal and Electricity Co., Ltd. The specific parameters of the coal mass are shown in Table 1:

Table 1 Industrial analysis parameters of pulverized coal

\begin{tabular}{lllll}
\hline Parameter & Volatile content & Ash content & Moisture content & True density \\
\hline Range & $9.87 \sim 10.97 \%$ & $11.53 \sim 19.13 \%$ & $0.56 \sim 2.55 \%$ & $1.5 \sim 1.53 \mathrm{~g} / \mathrm{cm}^{3}$ \\
\hline
\end{tabular}




\begin{tabular}{llllll}
\hline Parameter & Apparent density & Robustness coefficient & $\begin{array}{l}\text { Uniaxial } \\
\text { strength }\end{array}$ & Peak coal failure type \\
\hline Range & $1.34 \sim 1.38 \mathrm{~g} / \mathrm{cm}^{3}$ & $0.21 \sim 0.38$ & Less than $1 \mathrm{MPa}$ & Class III $\sim \mathrm{V}$ \\
\hline
\end{tabular}

In order to study the relationship between the immersion softening mechanism and mechanical parameters of coal, coal samples with different mechanical properties are prepared by configuring different coal sample components in this paper. Cement, sand, activated carbon, and coal powder of different particle sizes are used to prepare coal samples with a relatively uniform pore and fissure structure compared with that of the raw coal[ ${ }^{[28]}$.

Table 2 Composition of prepared coal sample

\begin{tabular}{cccccc}
\hline $\begin{array}{c}\text { Composition } \\
\text { ratio scheme }\end{array}$ & $\begin{array}{c}\text { Cement } \\
\text { (\#425 Ordinary } \\
\text { Portland Cement) }\end{array}$ & $\begin{array}{c}\text { Sand } \\
\text { (ordinary river } \\
\text { sand, particle size } \\
20-40 \text { mesh) }\end{array}$ & $\begin{array}{c}\text { Water } \\
\text { (pure } \\
\text { water) }\end{array}$ & $\begin{array}{c}\text { Activated } \\
\text { carbon } \\
\text { (granular, } \\
\left.\Phi 2.6 \times 5.6 \mathrm{~mm}^{2}\right)\end{array}$ & $\begin{array}{c}\text { Coal powder } \\
\text { (particle size 20-40 } \\
\text { mesh, 40-80 mesh, } \\
\text { ratio 1:1) }\end{array}$ \\
\hline 1 & 4 & 3.5 & 8.25 & 0.88 & 83.37 \\
2 & 5 & 6 & 7.75 & 0.7 & 80.55 \\
3 & 6 & 2.5 & 6.50 & 0.90 & 84.1 \\
4 & 7 & 5.5 & 8.50 & 0.84 & 78.16 \\
5 & 8 & 2 & 7.25 & 0.78 & 81.97 \\
\hline
\end{tabular}

\subsection{Preparation of water-immersed coal sample for dynamic mechanics test}

In order to study the mechanism of coal immersion softening, and to make the effect of immersion softening more obvious, three immersion schemes with a large gradient are designed: dry coal sample, coal sample with a moisture content of $30 \%$ and coal sample with a moisture content of $60 \%$. In order to avoid the influence of residual moisture in the production process, the coal sample in Section 2.1 is first dried, and then the coal sample that needs to be immersed is weighed. During the immersion process, the water does not need to be pressurized, that is, the coal sample is immersed in the water container. According to the moisture absorption capacity of the coal sample, a certain amount of water is absorbed to reach the moisture content required by the experiment. Finally, the soaked coal samples are wrapped in plastic wrap and put all into the storage box ready for the SHPB test.

\section{Experiment process and result analysis}

\subsection{Experiment process and results}

This test is mainly to study the influence of coal composition and water immersion on coal softening mechanism. Therefore, each type of water-bearing coal sample consists of 5 groups of coal samples with different components, and each group of 3 coal samples is subjected to repeated tests. After the SHPB test is conducted on the coal samples with different moisture contents, the stress, strain, and strain rate of the samples are calculated by the "dual wave method" ${ }^{[4]}$. Through data processing, the changes in the stress, strain, strain rate and energy of the 
coal sample over time are obtained ${ }^{[45]}$.

$$
\left\{\begin{array}{c}
\varepsilon_{*}(t)=-\frac{2 C}{l_{0}} \varepsilon_{r}(t) \\
\varepsilon(t)=-\frac{2 C}{l_{0}} \int_{0}^{t} \varepsilon_{r}(t) d_{t} \\
\sigma(t)=\frac{A}{A_{0}} E \varepsilon_{r}
\end{array}\right.
$$

where $\mathrm{C}$ is the elastic wave velocity, $\mathrm{E}$ is the elastic modulus, $\mathrm{A}$ is the cross-sectional area of the compression bar, $l_{0}$ is the length of the test sample, $\mathrm{A}_{0}$ is the cross-sectional area of the test sample, $\varepsilon_{\mathrm{r}}$ is the measured strain from the reflected waves, $\sigma$ is the measured stress .

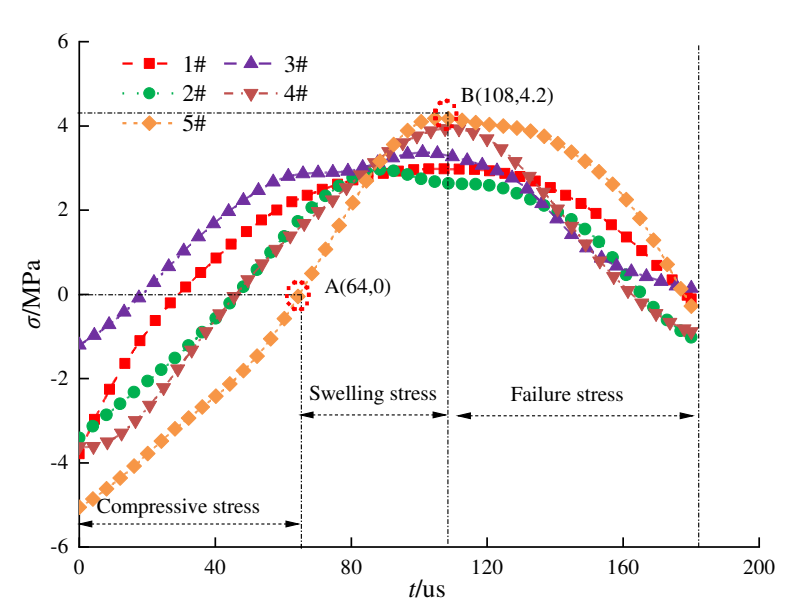

(a) Variation of stress with impact time

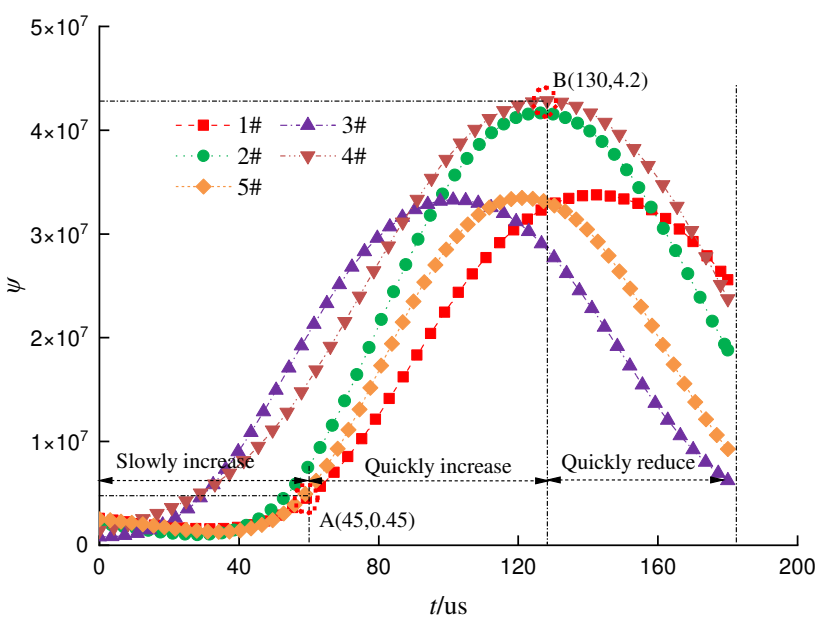

(c) Variation of strain rate with impact time

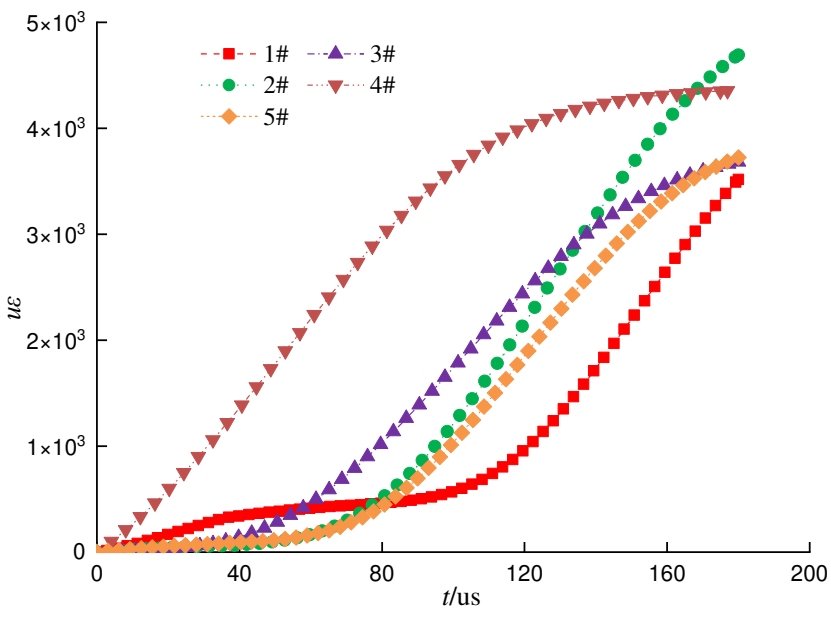

(b) Variation of strain with impact time

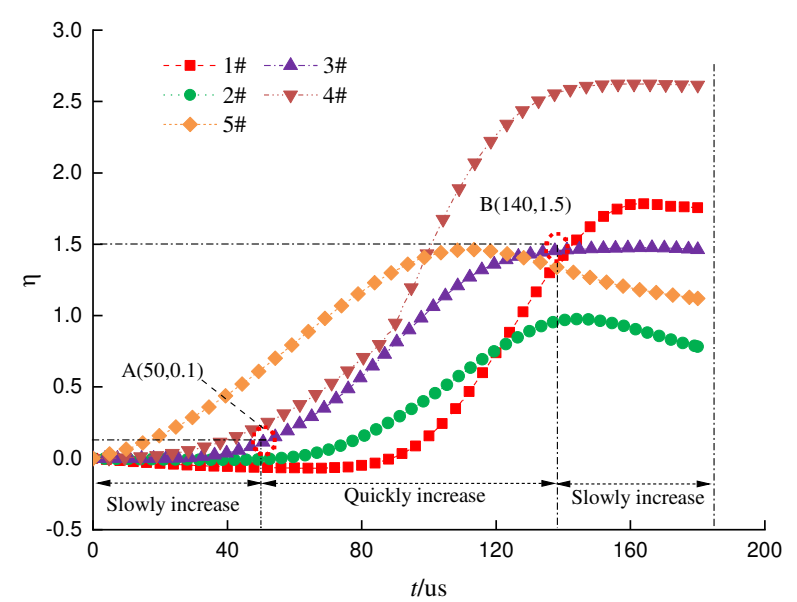

(d) Variation of energy dissipation with impact time

Figure 3 Dynamic mechanical characteristics of coal with a water content of $0 \%$

Figure 3 shows the stress, strain and energy dissipation of the dry coal sample within 180 us. This figure indicates that the stress, strain rate and energy dissipation of the coal sample show a trend of first increasing and then decreasing over time while the strain almost always increases. Figure 3 (a) shows the change of coal sample stress with time, where the negative stress is defined as the compressive stress, and the positive stress as the expansion stress. At first, the stress increases with time. After reaching the turning point, it begins to decrease and 
becomes the failure stress. Figure 3 (b) shows the variation of coal sample strain with time. For the $\# 3$ and $\# 5$ coal samples, the strain first increases slowly, then rapidly, and finally slowly. However, this change is not obvious for other coal samples. Figure 3 (c) shows the change of the strain rate of the coal sample with time. Compared with the stage change of the stress and strain, the stage change of the strain rate is more obvious. However, the turning points between the stages are different due to the influence of the composition of the coal sample. Figure 3 (d) shows the time variation of the energy dissipation of the coal sample during the entire destruction process. Combined with Figure 3 (b), it can be seen that the coal sample consumes a lot of energy during the large deformation stage.

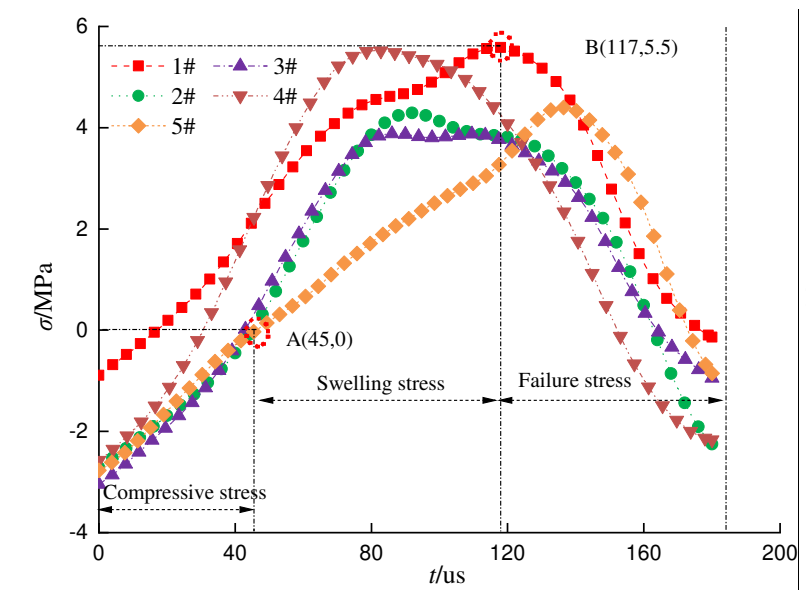

(a) Variation of stress with impact time

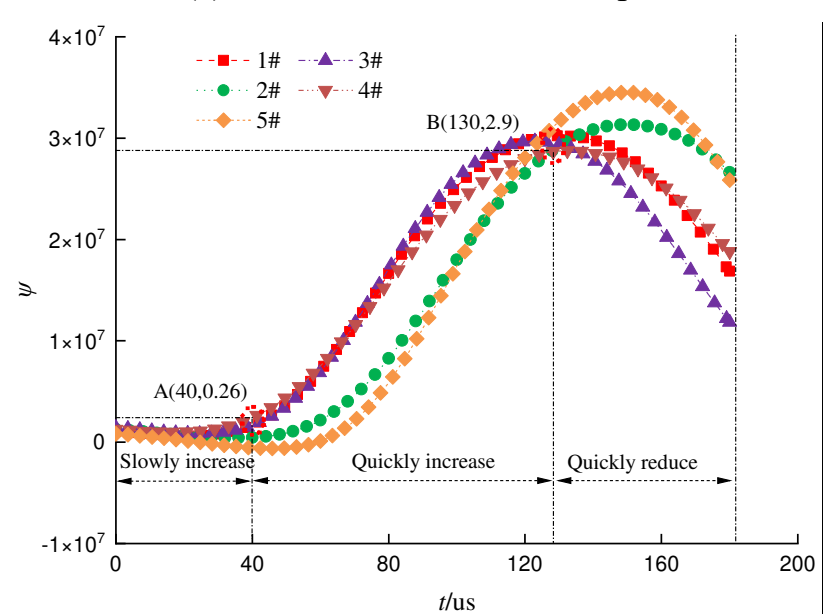

(c) Variation of strain rate with impact time

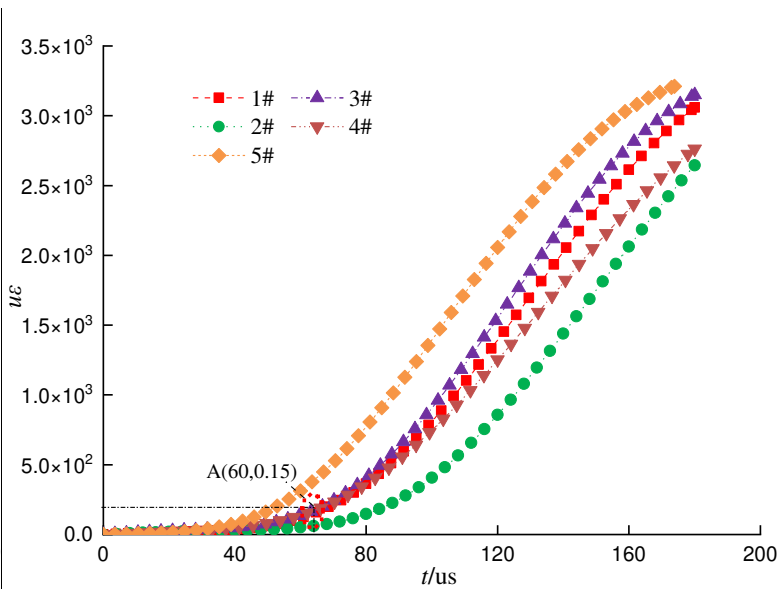

(b) Variation of strain with impact time

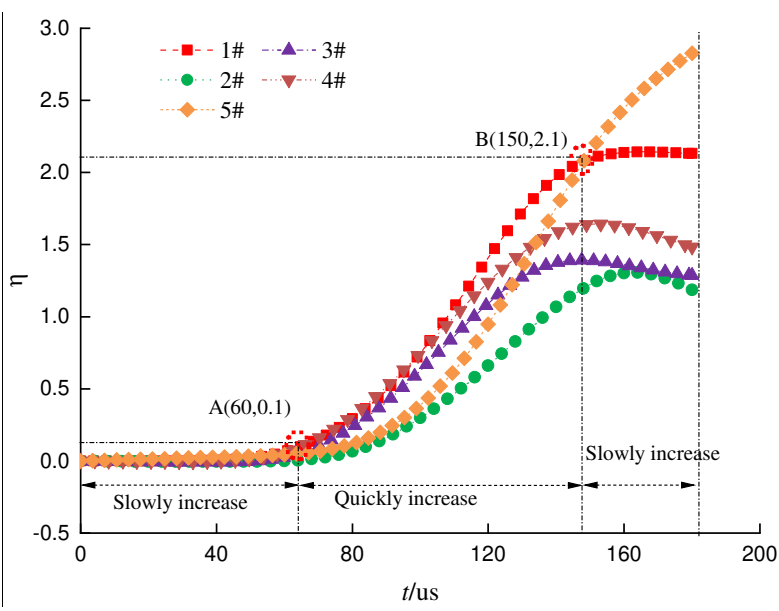

(d) Variation of energy dissipation with impact time

Figure 4 Dynamic mechanical characteristics of coal with a water content of $30 \%$

Figure 4 shows the stress, strain and energy dissipation of the coal sample with a water content of $30 \%$. Compared with the change rule of the dry coal sample, the characteristic rule of the four parameters of the coal sample is more obvious. From the overall analysis, the effect of coal immersion is regular, especially the evolution of the strain of the coal sample over time ${ }^{[33]}$. In Figure 4 (a), a "plateau" appears for the \#1, \#2, and \#3 coal samples after the swelling stress is generated in the coal sample, indicating that the internal moisture of the coal sample has a certain buffer effect on the deformation of the coal sample. Figure 4 (b) shows that the strain of the coal sample 
has a trend of slow increase before 60 us owing to the influence of water immersion. After the rapid increase afterwards, the coal samples of 5 different compositions have a trend of slow increase again ${ }^{[37]}$. Figure 4 (c) indicates that the strain rate change curve of the coal sample is similar to that of the dry coal sample. The strain rate of the coal sample is in a slow increase stage within the first 45 us, and then enters a rapid increase stage until 130 us. Further analysis of the strain rate of the coal sample indicates that the strain rate changes in the slow growth zone, the rapid growth zone and the rapid decline zone are more obvious than those of the dry coal sample. This means that water can promote an increase of internal deformation of the coal sample. Figure 4 (d) shows the energy dissipation during the entire destruction process of the coal sample. Compared with the energy dissipation of the dry coal sample, the slow growth stage of energy dissipation takes longer. In addition, the rapid growth stages of the five coal samples with a water content of $30 \%$ are more regular, indicating that water can activate the coal samples to absorb energy.

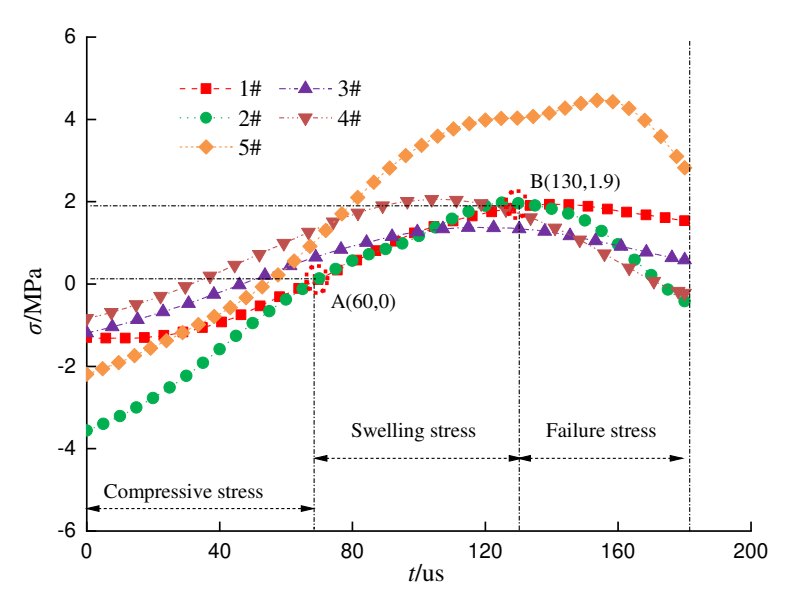

(a) Variation of stress with impact time

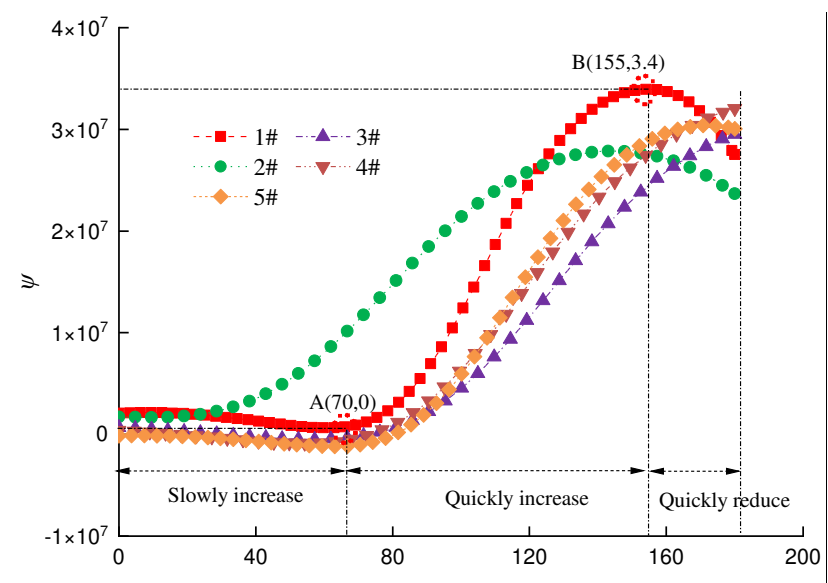

t/us

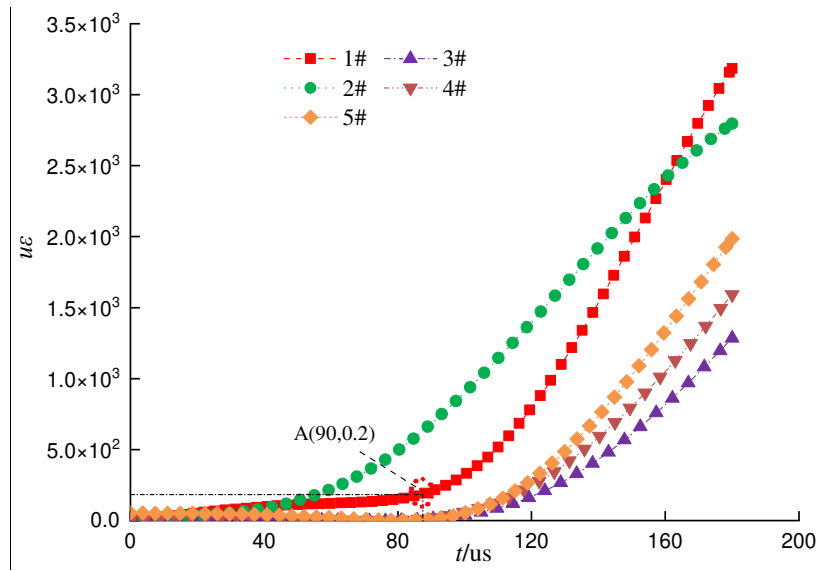

(b) Variation of strain with impact time

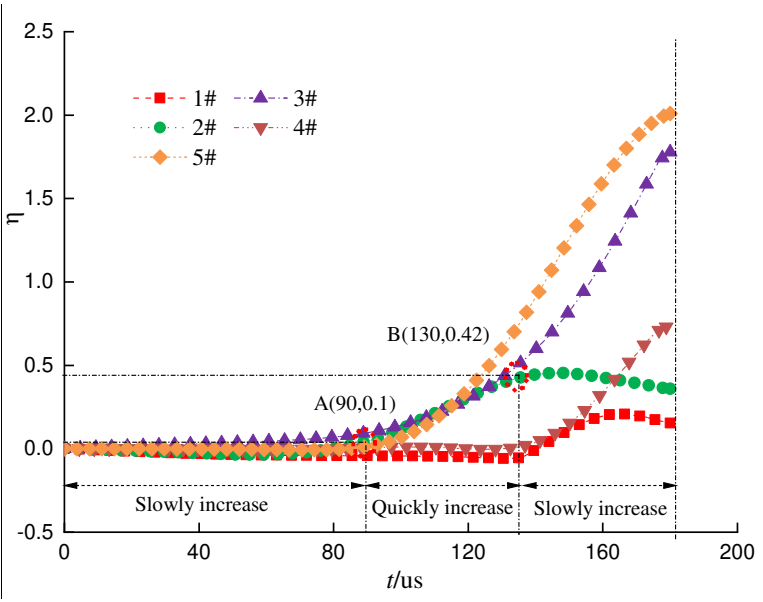

(d) Variation of energy dissipation with impact time

(c) Variation of strain rate with impact time

Figure 5 Dynamic mechanical characteristics of coal with a water content of $60 \%$

Figure 5 shows the variation of stress, strain and energy dissipation over time when the moisture content of the coal sample increases to $60 \%$. As indicated in Figure 4 (a) and Figure 5 (a), when the water content of the coal 
sample increases from $30 \%$ to $60 \%$, the stress "plateau" of the coal sample disappears, the compressive stress stage becomes longer, and the expansion stress stage becomes shorter. In addition, the failure stress stage is also significantly shortened. By comparison of Figure 4 (b) and Figure 5 (b), it is found that with the increase of the water content, the first slow increase stage of the strain becomes longer, and the rapid increase stage does not change much, but the second slow increase stage disappears. Figure 5 (c) shows a more obvious interval variation and the variation patterns of the five coal samples are also more uniform. From the change of strain rate with time alone, the effect of water immersion on the coal sample with a water content of $60 \%$ is more obvious than that on the coal samples with a water content of $0 \%$ and $30 \%$. Figure 5 (d) shows the energy dissipation curve of coal sample destruction. When the water content increases to $60 \%$, the first slow increase interval of energy dissipation increases, and the rapid increase interval and the second slow increase interval decrease, indicating that the energy consumed during the destruction process of coal mass is reduced after the coal mass is immersed in water.

\subsection{Analysis of test results}

\subsubsection{Analysis of immersion softening mechanism of coal mass on microscopic scale}

According to classic damage mechanics, the Drucker-Prager failure criterion has the advantages of simple parameter form and wide application in rock materials. When the rock is damaged by a three-way force, the strength of each component is ${ }^{[46]}$ :

$$
\left\{\begin{array}{r}
I_{1}=\sigma_{1}^{*}+\sigma_{2}^{*}+\sigma_{3}^{*} \\
J_{2}=\frac{1}{6}\left[\left(\sigma_{1}^{*}-\sigma_{2}^{*}\right)^{2}-\left(\sigma_{2}^{*}-\sigma_{3}^{*}\right)^{2}-\left(\sigma_{3}^{*}-\sigma_{1}^{*}\right)^{2}\right]
\end{array}\right.
$$

Under the condition of triaxial stress, $\sigma_{\mathrm{i}}^{*}(\mathrm{i}=1,2,3)^{[13]}$, when there is no fluid inside the rock, the triaxial stress forms an effective stress, and thus the corresponding strain $\varepsilon_{\mathrm{i}}^{*}(\mathrm{i}=1,2,3)^{[47]}$ is generated. According to Hooke's law:

$$
\varepsilon_{1}=\frac{1}{E}\left(\sigma_{1}^{*}-\mu \sigma_{2}^{*}-\mu \sigma_{3}^{*}\right)
$$

where $\mu$ is the Poisson's ratio of the rock, $\mathrm{E}$ is the initial elastic modulus, and $\varepsilon_{1}$ is the axial strain of the rock.

Then the effective damage stress of the rock is ${ }^{[48]}$ :

$$
\sigma_{1}^{*}=\sigma_{i} /(1-D),(i=1,2,3)
$$

where $\mathrm{D}$ is the statistical damage variable.

The statistical damage variable $\mathrm{D}$ is defined as follows:

$$
\mathrm{D}=\frac{N_{a}}{N}
$$

where $\mathrm{N}$ is the number of micro-units that the rock can be divided into, and $\mathrm{Na}$ is the number of damaged microunits in the rock.

Assuming that the micro-units obey the Weibull distribution, the density function of the number of damaged 
micro-units in the rock is:

$$
\mathrm{P}\left(F_{1}\right)=\frac{m}{F_{0}}\left(\frac{F_{1}}{F_{0}}\right) e^{\left[-\left(\frac{F_{1}}{F_{0}}\right)^{m}\right]}
$$

where $F_{0}$ and $m$ are the Weibull distribution parameters, and $F_{1}$ is the strength variable of the rock micro-unit at the first failure point.

Then the damage of $\mathrm{dF}_{1}$ extends to the inside of the rock. At this time, the failure interval of the rock is $\left(\mathrm{F}_{1}\right.$, $\left.\mathrm{F}_{1}+\mathrm{dF}_{1}\right)$, and the number of micro-units damaged inside the rock is $\mathrm{NP}(\mathrm{x})$, that is, the total number of damaged micro-units when the rock is stressed is:

$$
\mathrm{N}(F)=\int_{0}^{F_{1}} N P(x) d x=N\left\{1-\exp \left[-\left(\frac{F_{1}}{F_{0}}\right)^{m}\right]\right\}
$$

After Equation (7) is substituted into Equation (6), the damage variable D of the rock can be obtained as ${ }^{[30]}$ :

$$
\mathrm{D}=1-\exp \left[-\left(\frac{F}{F_{0}}\right)^{m}\right]
$$

Therefore, further substituting Equation (4) into Equation (3), we can obtain:

$$
\varepsilon_{1}=\frac{\sigma_{1}-\mu \sigma_{2}-\mu \sigma_{3}}{E(1-D)}
$$

Combining Equation (9) and Equation (4) together, we get:

$$
\sigma_{1}^{*}=\frac{\sigma_{i} E \varepsilon_{1}}{\sigma_{1}-\mu \sigma_{2}-\mu \sigma_{3}},(i=1,2,3)
$$

When the coal mass is immersed in water, the water moves in the fissure structure of the coal mass in a laminar flow, and performs capillary or diffusion movement in the smaller pores. Therefore, capillary force or self-suction force is introduced into the water-immersed coal mass. Assuming that water produces capillary force inside the pores of the coal sample and surface tension on the surface of the water, the force of water will exist in the form of "liquid bridge force". This means that when moisture condenses in the pores between the pulverized coal particles, the moisture and the particles form a common micro-unit force body. With more and more water in the pores, the thickness of the water film between the particles increases, and the formed liquid bridge force also increases, thereby increasing the cohesive force between the pulverized coal particles. However, there is a certain upper limit for the self-suction of the pores. When the water film increases to a certain thickness, the change in this cohesive force decreases. From a microscopic point of view, there are many influencing factors, such as the viscosity coefficient of the liquid and the distance between the pulverized coal particles. In the case of an infinitesimal body, the liquid bridge force inside the infinitesimal body is simplified to:

$$
\sigma_{w}=\sigma_{w 1}+\sigma_{w 2}
$$

where $\sigma_{\mathrm{w}}$ is the liquid bridge force inside the micro-unit body, $\sigma_{\mathrm{w} 1}$ is the static liquid bridge force of the micro-unit body, and $\sigma_{\mathrm{w} 2}$ is the dynamic liquid bridge force of the micro-unit body. 
The expressions of the two liquid bridge forces are ${ }^{[49]}$ :

$$
\left\{\begin{array}{c}
\sigma_{w 1}=2 \pi \varphi-\pi \varphi^{2} \gamma\left(\frac{1}{\varphi}+\frac{1}{\omega}\right) \\
\sigma_{w 2}=\frac{3}{2} \pi \epsilon R \vartheta
\end{array}\right.
$$

where $\varphi$ is the distance between the pulverized coal particles, $\omega$ is the contact angle between the pulverized coal particles and water, and $v$ is the viscosity coefficient of water.

Usually the dimensionless tension parameter $\mathrm{Ca}$ is used to measure the ratio of dynamic liquid bridge force to static liquid bridge force:

$$
C_{a}=\frac{\mu_{l} \cdot v_{r}}{\gamma}
$$

Assuming that the temperature is $20^{\circ} \mathrm{C}$. At this temperature, the surface tension coefficient $\gamma$ of water is $0.07275 \mathrm{~N} / \mathrm{m}$, the viscosity coefficient $\mu_{l}$ is $1.01 \times 10^{3} \mathrm{~N} \cdot \mathrm{s} \cdot \mathrm{m}^{2}$, and the maximum value of the relative velocity between particles $v_{r}$ is $2.084 \mathrm{~m} / \mathrm{s}$. In this paper, only the capillary force, i.e., the static liquid bridge force is considered in the calculation of the liquid bridge force. Therefore, assuming that the adhesion force between pulverized coal particles and water is a liquid bridge force, the calculation equation is:

$$
\frac{\sigma_{w}}{a}=2 \pi \sigma_{\gamma} \cos \theta_{p}
$$

where $\sigma_{\gamma}$ is the surface tension of water, and $\theta_{p}$ is the contact angle between coal particles and water.

The calculation equation of the liquid bridge force is further transformed into:

$$
\frac{\sigma_{w}}{a}=\frac{2 \pi \sigma_{\gamma} \cos \theta_{p}}{(1+H / 2 d)}
$$

where $a$ is the radius of the pulverized coal particles, $\mathrm{H}$ is the length of the liquid bridge or the distance between two pulverized coal particles, and $\mathrm{d}$ is the immersion height of the liquid bridge or the height of the pulverized coal particles that can be wrapped by water to remove the surface tension.

\subsubsection{Analysis of macroscopic strength failure based on microscopic coal immersion softening}

Combined with the strength analysis of the rock micro-unit body, the macro-strength criterion of the unimmersed coal sample is derived as follows. Using the Lemaitre equivalent strain principle, we obtain:

$$
\sigma=\mathrm{E} \varepsilon_{1}(1-D)+\mu\left(\sigma_{2}+\sigma_{3}\right)
$$

Substituting Equation (8) into Equation (16), we get ${ }^{[50]}$ :

$$
\sigma=\mathrm{E} \varepsilon_{1} p\left[-\left(\frac{F_{1}}{F_{0}}\right)^{m}\right]+\mu\left(\sigma_{2}+\sigma_{3}\right)
$$

\footnotetext{
After further substituting into Equation (2) and simplifying, we have ${ }^{[51]}$ :
} 


$$
\left\{\begin{array}{l}
I_{1}=\frac{\sigma_{1}+\sigma_{2}+\sigma_{3}}{\sigma_{1}-\mu \sigma_{2}-\mu \sigma_{3}} \\
J_{2=\frac{1}{6}}\left[\left(\frac{\sigma_{1}-\sigma_{2}}{1-D}\right)^{2}+\left(\frac{\sigma_{2}-\sigma_{3}}{1-D}\right)^{2}+\left(\frac{\sigma_{3}-\sigma_{1}}{1-D}\right)^{2}\right]
\end{array}\right.
$$

Assuming $\sigma_{2}=\sigma_{3}=0$, that is, the coal sample is subjected to uniaxial stress. At this time, without considering the influence of water, we obtain the strength damage model of the coal sample ${ }^{[45]}$ :

$$
\left\{\begin{array}{l}
\quad \sigma=\mathrm{E} \varepsilon_{1} p\left[-\left(\frac{F_{1}}{F_{0}}\right)^{m}\right] \\
I_{1}=\mathrm{E} \varepsilon_{1} \\
J_{2}=\frac{1}{6}\left(\mathrm{E} \varepsilon_{1}\right)^{2}
\end{array}\right.
$$

When the immersed coal sample is under uniaxial compression, its strength damage model is:

$$
\left\{\begin{array}{l}
\quad \sigma=\mathrm{E} \varepsilon_{1} p\left[-\left(\frac{F_{1}}{F_{0}}\right)^{m}\right]+\mu \sigma_{w} \\
I_{1}=\frac{\sigma_{1}+\mu \sigma_{w}}{\sigma_{1}-\mu \sigma_{w}} \\
J_{2}=\frac{1}{6}\left[\left(\mathrm{E} \varepsilon_{1}\right)^{2}\right]
\end{array}\right.
$$

It can also be expressed as:

$$
\left\{\begin{array}{l}
\sigma=\mathrm{E} \varepsilon_{1} p\left[-\left(\frac{F_{1}}{F_{0}}\right)^{m}\right]+2 \pi \mu a \frac{\sigma_{\gamma} \cos \theta_{p}}{(1+H / 2 d)} \\
I_{1}=1+\frac{4 \pi \mu a \sigma_{\gamma} \cos \theta_{p}}{\sigma_{1}(1+H / 2 d)-2 \pi \mu a \sigma_{\gamma} \cos \theta_{p}} \\
J_{2}=\frac{1}{6}\left[\left(\mathrm{E} \varepsilon_{1}\right)^{2}\right]
\end{array}\right.
$$

Figure 6 shows the transformation relationship between compressive stress, swelling stress and failure stress of the coal samples with different water contents. When the water content of the coal sample increases from $0 \%$ to $60 \%$, the failure stress interval of the five coal samples decreases while the expansion stress interval increases. However, there is no uniform relationship between changes in the compressive stress interval. This means that after the coal sample is immersed in water, the water inside the coal sample helps increase the swelling stress interval of the coal sample. For the $\# 2$ and $\# 5$ coal samples, the above-mentioned change characteristics are particularly obvious. From the analysis of coal sample composition, in the \#2 coal sample the proportion of activated carbon is $0.7 \%$ and the proportion of pulverized coal is $80.55 \%$, while in the $\# 5$ coal sample the proportion of activated carbon is $0.78 \%$ and the proportion of pulverized coal is $81.97 \%$. The two components of the two coal samples are similar to those of the other coal samples.

For different moisture contents, as the moisture increases from $0 \%$ to $30 \%$, the coal particles are gradually wetted by the moisture. Because the wet coal particles gradually agglomerate, the cohesion between the pore and 
fissure structures of the coal mass is increased, and thus the compressive strength of the briquette is enhanced to a certain extent. When the moisture content of the coal sample is $60 \%$, the pulverized coal particles are gradually surrounded by the moisture. As a result, the cohesion is reduced, and the compressive strength of the coal sample may be also reduced. The above impact compression test shows that the compressive strength of coal samples and the overall proportion of different stages are closely related to moisture. In addition, the ratio of activated carbon to pulverized coal has an important influence on the compressive stress, expansion stress and failure stress of the coal sample. The greater the ratio of activated carbon to pulverized coal, the more obvious the transformation of the three stresses, as shown in Figure 6.
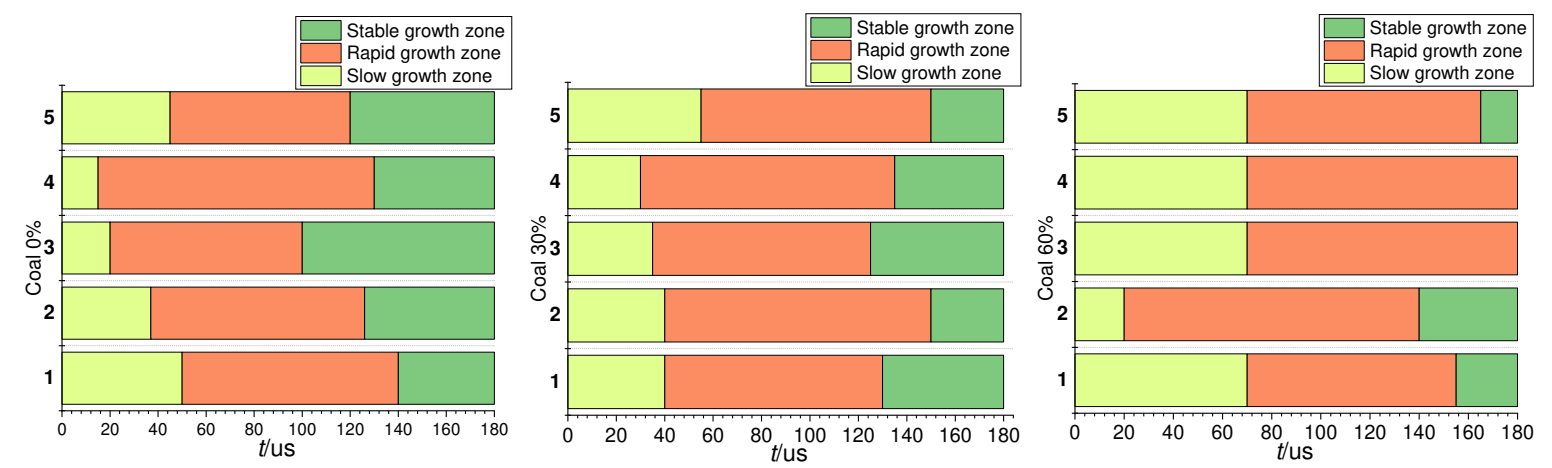

Figure 6 Influence of moisture content of coal sample on transformation of stress properties

Figure 7 shows the impact failure modes of the coal samples with different moisture contents. It can be clearly seen that when the water content is $0 \%, 30 \%$ and $60 \%$, the \#1-\#5 coal samples all undergo longitudinal compression failure. And from one end of the incident rod, obvious cracks were generated, until the coal sample was completely destroyed. However, when the moisture content of the coal sample increases, the coal sample is impacted by the incident rod, the middle part of the coal sample begins to expand and deform, and one end of the transmission rod also begins to break. The failure mode changes from damage on one side to damage on both sides.

According to the theoretical analysis of microscopic coal mass water soaking softening, when the amount of combined with each other, thereby promoting the agglomeration of coal particles and increasing the overall cohesive force of the coal ${ }^{[15]}$. When the pulverized coal particles are subjected to an impact force, greater force is required to separate the particles. The above is the process of transforming the macroscopic impact force of the coal mass into the microscopic separation force of the pulverized coal particles. When the amount of water added to the dry coal particles exceeds the reasonable range, the volume of the liquid bridge formed between the particles increases. However, the volume of the pore structure between the particles is ultimately limited, and thus more moisture will gradually wrap the particles, allowing the liquid to penetrate. This process reduces the cohesive force between the particles. If the coal sample is subjected to an external impact load, it is more prone to instability and damage. From 
the analysis of energy consumption of the coal samples with different moisture contents, the microscopic liquid bridging force between particles and water can reflect the macroscopic failure mode of the coal samples.

Through theoretical and experimental analysis, the degree of coal sample softening by immersion in water is affected by the composition of the coal sample, especially the components of cement and activated carbon in the coal sample. The greater the proportion of the cement component in the coal sample, the more obvious the softening degree of the coal sample, and the smaller the influence of the activated carbon component. Therefore, the microscopic effect of moisture on coal samples can be reflected from the macroscopic point of the experiment.
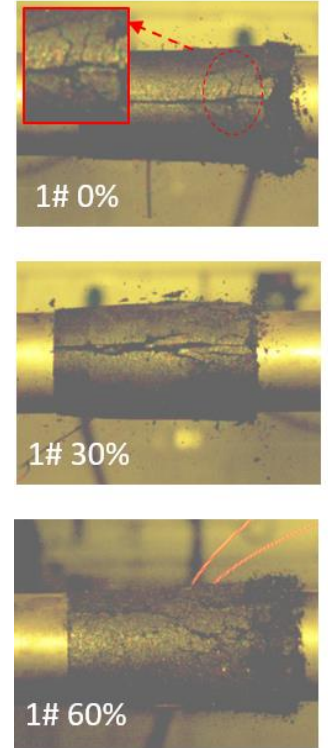
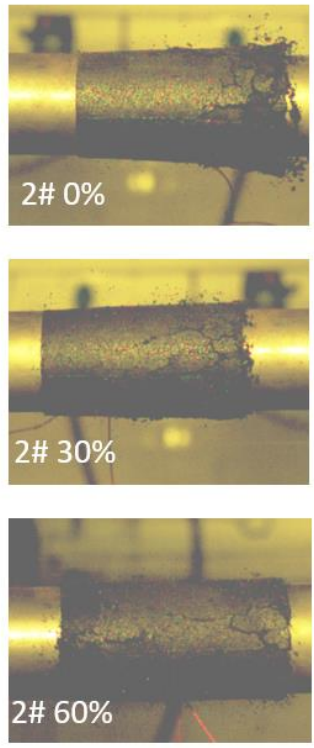
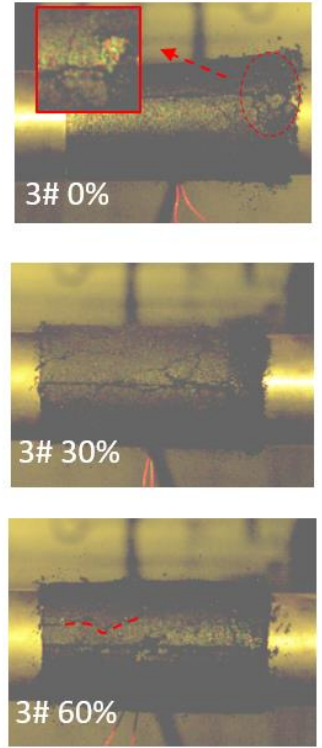
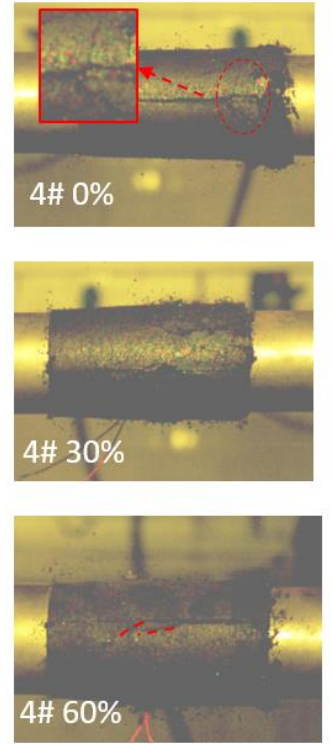
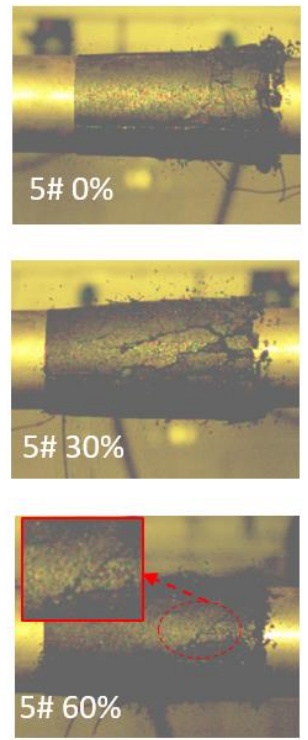

\section{Figure 7 Effect of coal sample immersion on transformation of stress properties}

Figure 8 shows the strain rate change of the coal samples with three different moisture contents and five compositions. In this figure, the strain rates of the $\# 1$ and $\# 5$ coal samples are used as reference values, and there is no obvious change and uniformity change in the rapid growth area. From the overall analysis, as the water content increases, the interval of the slow growth area increases while the interval of the stable growth area decreases. Especially when the water content of the coal sample is $60 \%$, there is no stable growth area in the \#3 and \#4 coal samples. From the analysis of the composition of the coal samples, the proportions of coal particles and sand in the $\# 1$ and \#5 coal samples are the same, but the cement component gradually increases. Therefore, when the coal sample has high moisture content, the deformation of the coal sample is affected. 

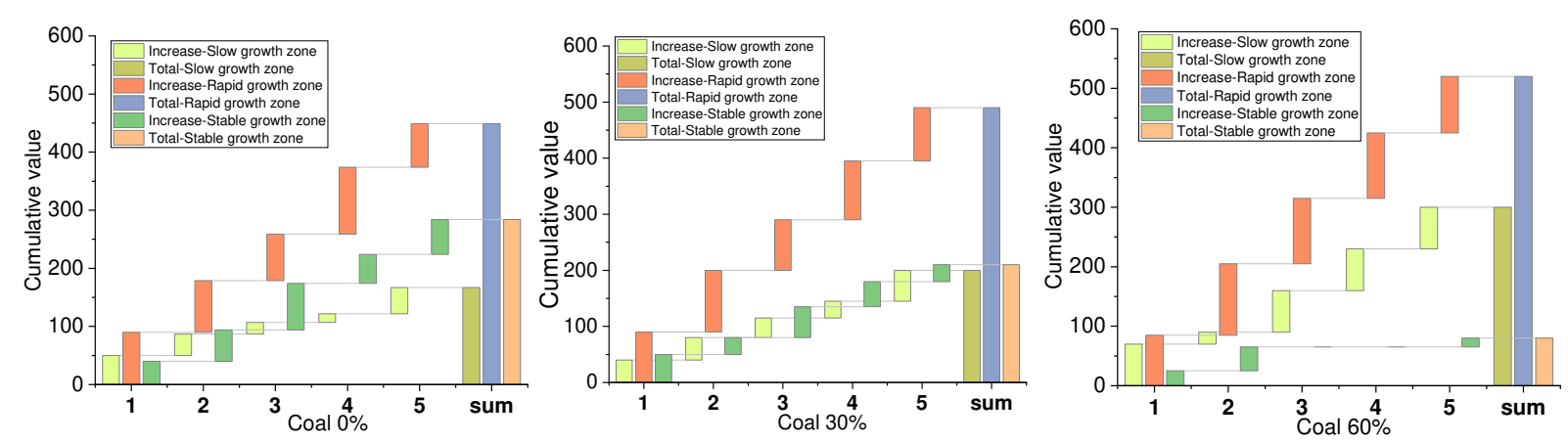

Figure 8 Strain rate changes of coal samples with three different moisture contents

From the analysis of the energy of the coal sample, the energy change of the coal sample during the entire destruction process is obvious, and it mostly occurs after 50 us. In the early stage, there is a process of energy accumulation. After the coal sample is destroyed, the energy is rapidly reduced. This experiment shows that reasonable moisture can promote the agglomeration of dry coal particles. When the moisture exceeds certain content, the agglomeration effect of moisture on coal particles is weakened.

In summary, the composition ratios of the \#3 and \#4 coal samples are not suitable for water immersion experiments on coal with high water content. In the case of the three water contents, the slow growth interval of Coal Sample \#1 is relatively long, and thus Coal Sample \#1 is used for the coal immersion softening experiment because it has the best composition ratio.

\section{Conclusions}

In this paper, the SHPB experiment was carried out on five coal samples with three different moisture contents, and the dynamic characteristics and energy dissipation of water-immersed coal with different compositions and water contents were analyzed. After analysis and discussion, the following conclusions are drawn:

(1) When the moisture content of the coal sample is $0 \%, 30 \%, 60 \%$, the stress, strain rate, and energy dissipation of the coal sample first increase and then decrease with time while the strain of the coal sample almost increases all the time with slow growth stages and rapid growth stages.

(2) When the water content of the coal sample increases from $30 \%$ to $60 \%$, the stress "plateau" of the coal sample disappears, the interval of the compressive stress increases, and the interval of the expansion stress decreases.

(3) The increase of water content of coal will affect the impact deformation and failure mode of coal. When the water content is $0 \%$ and $30 \%$, the coal sample undergoes compression deformation and destruction from one end of the incident rod; but when the water content is $60 \%$, the middle part of the coal sample shows expansion and deformation. 
Ordinary Portland Cement: 4\%, River sand (20-40 mesh): 3.5\%, water: 8.25\%, Granular activated carbon $\Phi 2.6 \times 5.6$ $\mathrm{mm}^{2}: 0.88 \%$, Coal powder $(20-40,40-80$ mesh ratio $1: 1): 83.37 \% \%$.

\section{Funding and Acknowledgements}

This research was funded by the National Natural Science Foundation of China （51974176、51934004); Shandong Province Natural Science Foundation of Outstanding Youth Fund (Grant No. ZR2020JQ22); Shandong Province Colleges and Universities Youth Innovation and Technology Support Program (Grant No. 2019KJH006); Taishan Scholars Project (TS20190935)

\section{Competing interests}

We declare that we have no financial and personal relationships with other people or organizations that can inappropriately influence our work, there is no professional or other personal interest of any nature or kind in any product, service and/or company that could be construed as influencing the position presented in, or the review of, the manuscript entitled.

\section{Authors' contributions}

Gang Wang and Zhiyuan Liu interpreted the results and wrote the manuscript. Jinzhou Li, Haifeng Zhao and Huaixing Li conceived and designed the experiments and theoretical models; Hongwei Shi and Jianli Lan performed the experiments; All authors gave final approval for publication.

\section{References}

[1] FAN L, MA L, YU Y 等. Water-conserving mining influencing factors identification and weight determination in northwest China[J]. International Journal of Coal Science and Technology, Springer Singapore, 2019, 6(1): 95-101.

[2] BOQUAN L, SHINING Z. Experimental Investigation on the Deformation Law of Coal Body Containing Methane[J]. Journal of China Institute of Mining and Technology, 1986, 3: 9-16.

[3] WANG G, LI J, LIU Z等. Relationship between wave speed variation and microstructure of coal under wet conditions[J]. International Journal of Rock Mechanics and Mining Sciences, Elsevier Ltd, 2020, 126(January): 104203.

[4] LAMA R D, BODZIONY J. Management of outburst in underground coal mines[J]. International Journal of Coal Geology, 1998, 35: 83-115.

[5] J D, W Z, Z L. The examination study of the size-composition of the fine-coal briquetting[J]. Journal of China Coal Society, 2005, 1(30): 100-103.

[6] JIANG X U, DONG L I U, SHOUJIAN P等. EXPERIMENTAL RESEARCH ON INFLUENCE OF PARTICLE DIAMETER[J]. Chinese Journal of Rock Mechanics and Engineering, 2010, 29(6): 12311237.

[7] YU M G, CHAO J K, CHU T X等. Experimental study on permeability parameter evolution of pressure-bear broken coal[J]. Journal of the China Coal Society, 2017, 42(4): 916-922.

[8] WOLF K, BRUINING H. Modelling the interaction between underground coal fires and their roof 
rocks[J]. Fuel, 2007, 86: 2761-2777.

[9] ZHAO D, LI X, TANG Y等. Study of gas adsorption characteristics influenced by moisture Geosciences, 2020, 13(15).

[10] JIANG X, QI L, XIN W等. The fractal characteristics of the pore and development ofbriquettes with different coal particle sizes[J]. Journal of Chongqing University, 2011, 9(34): 81-89.

[11] WANG G, JIANG C, SHEN J等. Deformation and water transport behaviors study of heterogenous coal using CT-based 3D simulation[J]. International Journal of Coal Geology, Elsevier, 2019, 211(May): 103204.

[12] ERGULER Z A, ULUSAY R. Water-induced variations in mechanical properties of clay-bearing rocks[J]. International Journal of Rock Mechanics \& Mining Sciences, 2009, 46: 355-370.

[13] KAI W. Mechanical properties and statistical damage model of coal with different moisture contents under uniaxial compression[J]. 2018(2016).

[14] KIM E, BASTOS D, OLIVEIRA M De. The Effects of Water Saturation on Dynamic Mechanical Properties in Red and Buff Sandstones Having Different Porosities Studied with Split Hopkinson Pressure Bar ( SHPB )[J]. 2015, 753: 784-789.

[15] CHANGBAO J, MINKE D, GUANGZHI Y等. Loading- unloading experiments of coal containing gas under the condition of different moisture contents[J]. Journal of China Coal Society, 2016, 41(9): 2230-2237.

[16] BOBO L, ZHONGHUI W, CHONGHONG R等. Mechanical properties and damage constitutive model of coal under the coupled hydro-mechanical effect[J]. Rock and Soil Mechanics, 2021, 42(2): 315-332.

[17] YIN G, JIANG C, XU J等. An Experimental Study on the Effects of Water Content on Coalbed Gas Permeability in Ground Stress Fields[J]. Transport in Porous Media, 2012, 94(1).

[18] QIN H, HUANG G, WANG W. Experimental Study of Acoustic Emission Characteristics of Coal Samples With Different Moisture Contents in Process of Compression Deformation and Failure[J]. Chinese Journal of Rock Mechanics andEngineering, 2012, 31(6): 1115-1120.

[19] WOO S, KIM T. High strain-rate failure in carbon / Kevlar hybrid woven composites via a novel SHPB-AE coupled test[J]. Composites Part B, Elsevier Ltd, 2016, 97: 317-328.

[20] PAN Z, CONNELL L D, CAMILLERI M等. Effects of matrix moisture on gas diffusion and flow in coal[J]. Fuel, Elsevier Ltd, 2010, 89(11): 3207-3217.

[21] PERERA M S A, RANJITH P G, PETER M. Effects of saturation medium and pressure on strength parameters of Latrobe Valley brown coal : Carbon dioxide, water and nitrogen saturations[J]. Energy, Elsevier Ltd, 2011, 36(12): 6941-6947.

[22] ZUNGUO Z, DAN Z, YI C. Isothermal adsorption and swelling deformation characteristics of soft coal under different moisture content[J]. Journal of China Coal Society, 2020, 45(11): 3817-3824.

[23] XIAOCHUN X, CHEN J, XIN D等. Experimental study on rock burst tendency of coal with different moisture content based on acoustic emission time-frequency signals[J]. Journal of China Coal Society, 2018, 43(4): 931-938.

[24] SALEH M, KARIEM M M, LUZIN V等. High strain rate deformation of ARMOX 500T and e ff ects on texture development using neutron di ff raction techniques and SHPB testing[J]. Materials Science \& Engineering A, Elsevier B.V., 2018, 709(August 2017): 30-39.

[25] DARYADEL S S, RAY C, PANDYA T等. Energy Absorption of Pultruded Hybrid Glass / Graphite Epoxy Composites under High Strain-Rate SHPB Compression Loading[J]. Materials Sciences and Applications, 2015(June): 511-518.

[26] ZHU J, HU S, WANG L. An analysis of stress uniformity for concrete-like specimens during SHPB tests[J]. International Journal of Impact Engineering, Elsevier Ltd, 2009, 36(1): 61-72. 
[27] MISHRA S, KHETWAL A, CHAKRABORTY T. Dynamic Characterisation of Gneiss[J]. Rock Mechanics and Rock Engineering, Springer Vienna, 2019, 52(1): 61-81.

[28] DONER S, NAYAK S, SENOL K等. Dynamic compressive behavior of metallic particulatereinforced cementitious composites : SHPB experiments and numerical simulations[J]. Construction and Building Materials, Elsevier Ltd, 2019, 227: 116668.

[29] ROTH C C, GARY G, MOHR D. Compact SHPB System for Intermediate and High Strain Rate Plasticity and Fracture Testing of Sheet Metal[J]. 2015: 1803-1811.

[30] AI D, ZHAO Y, WANG Q等. Crack propagation and dynamic properties of coal under SHPB impact loading : Experimental investigation and numerical simulation[J]. Theoretical and Applied Fracture Mechanics, Elsevier, 2020, 105(August 2019): 102393.

[31] YIN Z, CHEN W, HAO H等. Dynamic Compressive Test of Gas - Containing Coal Using a Modified Split Hopkinson Pressure Bar System[J]. Rock Mechanics and Rock Engineering, Springer Vienna, 2020, 53(2): 815-829.

[32] HAO X, DU W, ZHAO Y等. Dynamic tensile behaviour and crack propagation of coal under coupled static-dynamic loading[J]. International Journal of Mining Science and Technology, China University of Mining \& Technology, 2020, 30(5): 659-668.

[33] KONG X, WANG E, LI S 等. Dynamic mechanical characteristics and fracture mechanism of gasbearing coal based on SHPB experiments[J]. Theoretical and Applied Fracture Mechanics, Elsevier, 2020, 105(August 2019): 102395.

[34] KONG X, LI S, WANG E等. Dynamics behaviour of gas-bearing coal subjected to SHPB tests[J]. Composite Structures, Elsevier Ltd, 2021, 256(September 2020): 113088.

[35] KONG X, LI S, WANG E等. Experimental and numerical investigations on dynamic mechanical responses and failure process of gas-bearing coal under impact load[J]. Soil Dynamics and Earthquake Engineering, Elsevier Ltd, 2021, 142(January): 106579.

[36] ZHAO Y, ZHAO G, JIANG Y等. Effects of bedding on the dynamic indirect tensile strength of coal : Laboratory experiments and numerical simulation[J]. International Journal of Coal Geology, Elsevier B.V., 2014, 132: 81-93.

[37] FENG J, WANG E, HUANG Q等. Experimental and numerical study of failure behavior and mechanism of coal under dynamic compressive loads[J]. International Journal of Mining Science and Technology, China University of Mining \& Technology, 2020, 30(5): 613-621.

[38] FENG J, WANG E, CHEN L等. Experimental study of the stress effect on attenuation of normally incident P-wave through coal[J]. Journal of Applied Geophysics, Elsevier B.V., 2016, 132: 25-32.

[39] FAN C, ELSWORTH D. Experimental investigation on dynamic strength and energy dissipation characteristics of gas outburst-prone coal[J]. 2020(September 2019): 1015-1028.

[40] CHENGWU L, QIFEI W, PINGYANG L. Study on electromagnetic radiation and mechanical characteristics of coal during an SHPB test[J]. Journal of Geophysics and Engineering, IOP Publishing, 2016, 13: 391.

[41] BIN W, XIBING L, TUBING M等. Split Hopkinson Pressure Bar(Shpb) Experiments on Dynamic Strength of Water-Saturated Sandstone[J]. Chinese Journal of Rock Mechanics and Engineering, 2010, 29(5): 1003-1009.

[42] XIAOHUI L, RU Z, JIANFENG L. Dynamic test study of coal rock under different strain rates[J]. Journal of China Coal Society, 2012, 37(9): 1528-1534.

[43] CHENGWU L, BEIJING X, WEI Y等. Coal impact damage SHPB testing signal de-noisingbased on HHT method[J]. Journal of China Coal Society, 2012, 37(11): 1796-1802.

[44] LARBI G, MOSTAPHA T, HOCINE O等. A practical note for SHPB test with new algorithms for delimiting pulses[J]. COMPOSITE STRUCTURE, Elsevier Ltd, 2015, 126: 145-158. 
[45] AL-SALlOUM Y, ALMUSALlAM T, IBRAHIM S M等. Cement \& Concrete Composites Rate dependent behavior and modeling of concrete based on SHPB experiments[J]. CEMENT AND CONCRETE COMPOSITES, Elsevier Ltd, 2015, 55: 34-44.

[46] REZA M, MOHAMMAD M. RESEARCH PAPER A Micromechanical Model for Simulation of Rock Failure Under High Strain Rate Loading[J]. International Journal of Civil Engineering, Springer International Publishing, 2021, 19(5): 501-515.

[47] JACQUELIN D B S R E. Estimating Measurement Uncertainty on Stress-Strain Curves from SHPB[J]. Experimental Mechanics, Experimental Mechanics, 2017, 57: 735-742.

[48] BUTT U, XUE P. Determination of the wave propagation coef fi cient of viscoelastic SHPB : Signi fi cance for characterization of cellular materials[J]. International Journal of Impact Engineering, 2014, 74: 8391.

[49] BARIANI P F, BERTI G, CORAZZA S. Enhancing performances of SHPB for determination of flow curves[J]. CIRP Annals, 2011, 50(1): 153-156.

[50] MERLE R, ZHAO H Ã. On the errors associated with the use of large diameter SHPB, correction for radially non-uniform distribution of stress and particle velocity in SHPB testing[J]. nternational Journal of Impact Engineering, 2006, 32: 1964-1980.

[51] TUAZON B J, BAE K, LEE S等. Integration of a new data acquisition / processing scheme in SHPB test and characterization of the dynamic material properties of high-strength steels using the optional form of Johnson-Cook model $\uparrow[\mathrm{J}]$. Journal of Mechanical Science and Technology, 2014, 28(9): 3561-3568. 